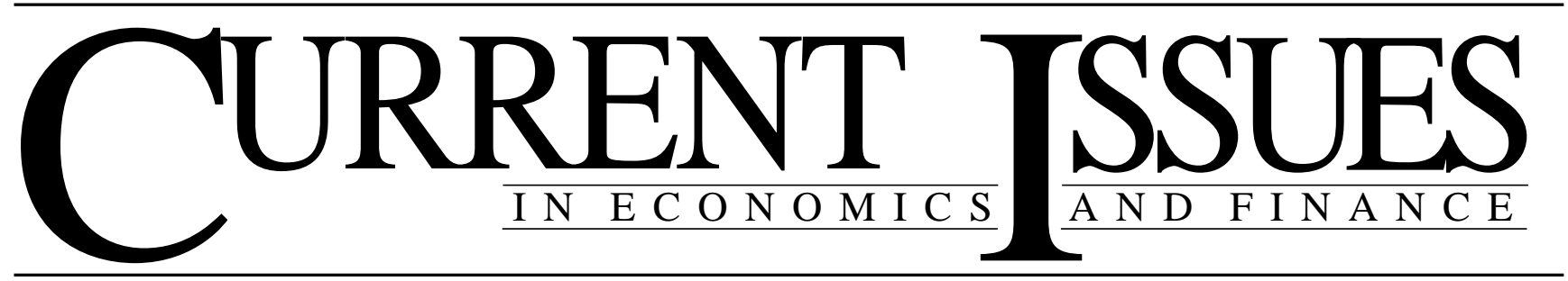

January 1998

Volume 4 Number 1

\title{
Electronic Trading on Futures Exchanges
}

Asani Sarkar and Michelle Tozzi

\begin{abstract}
Although the open outcry method is still the best way to trade highly active contracts on futures exchanges, electronic systems can improve the efficiency and cost effectiveness of trading some types of futures and options. In recent years, the volume of electronic trades on futures exchanges has more than doubled, and it should continue to grow rapidly.
\end{abstract}

Most futures exchanges are nonprofit organizations whose members include banks, investment houses, and independent traders. Futures exchanges provide exclusive access to centralized marketplaces where members buy and sell futures and options contracts for themselves and outside customers. ${ }^{1}$ In return for use of exchange facilities, members pay fees for each transaction. Members also pay indirect costs in the form of lost revenues when trading volume and frequency of trades are low, or a market is illiquid. Thus, the goal of an exchange is to minimize members' fees and ensure liquidity by generating high trading volume for the contracts listed on the exchange.

In the past, futures exchanges mostly relied on product innovation to generate trading volume. By introducing futures and options on popular assets such as U.S. Treasury instruments, futures exchanges successfully built trading volume. The introduction of futures and options on newer assets, however, has proved more challenging. Many of these assets tend to be more specialized and thus less likely to attract broad investor interest. The increase in the number of futures exchanges around the world and competition from over-the-counter markets have also put pressure on the volume of trades made on individual exchanges.

One way futures exchanges are attempting to boost trading volume and compete more effectively is by increasing their use of electronic trading systems. Indeed, from 1989 to 1996, volume on electronic trading systems used by futures exchanges more than doubled, rising from 7 percent of the world's trading volume to 18 percent (Price Waterhouse 1997).

What are the principal features of these new electronic trading systems? And how do these systems compare with the open outcry method of trading traditionally used by futures exchanges? This edition of Current Issues explores the advantages and disadvantages of the two types of trading methods and considers how futures exchanges are likely to evolve in an electronic age.

\section{Open Outcry Trading}

The largest organized futures exchanges in the worldmost notably, the Chicago Board of Trade (CBOT), the Chicago Mercantile Exchange (CME), and London's LIFFE - use the open outcry method of trading.

To place an order under this method, the customer calls a broker, who time-stamps the order and prepares an office order ticket. The broker then sends the order to a booth on the exchange floor. There, a floor order ticket is prepared, and a clerk hand delivers the order to the floor trader for execution. In some cases, the floor clerk may use hand signals to convey the order to floor traders. Large orders typically go directly from the customer to the broker's floor booth. 
The floor trader, standing in a central location called a trading pit, negotiates a price by shouting out the order to other floor traders, who bid on the order using hand signals. Once filled, the order is recorded manually by both parties to a trade. At the end of each day, the clearinghouse settles trades by ensuring that no discrepancy exists in the matched-trade information.

U.S. futures exchanges, where the open outcry method prevails, have dominated global futures and options trading. In recent years, however, the world market share held by U.S. exchanges has fallen dramatically: in 1997, U.S. exchanges accounted for 41 percent of the trading volume of exchange-traded products, compared with 65 percent in $1990 .^{2}$ During the same period, many new futures and options exchanges emerged abroad and trading volume on non-U.S. exchanges grew significantly (Chart 1). A feature shared by many of these new exchanges is the automated execution of trades.

\section{Electronic Trading Systems}

An automated trade execution system has three components: computer terminals, where customer orders are keyed in and trade confirmations are received, a host computer that processes trades, and a network that links the terminals to the host computer. Customers may enter orders directly into the terminal or phone in the order to a broker. Although order execution can occur in various ways, the electronic order-matching system is the most popular on futures exchanges. ${ }^{3}$

With electronic order-matching systems, the host computer matches bids with offers according to certain rules

\section{Chart 1 \\ Volume of Exchange-Traded Futures and Options}

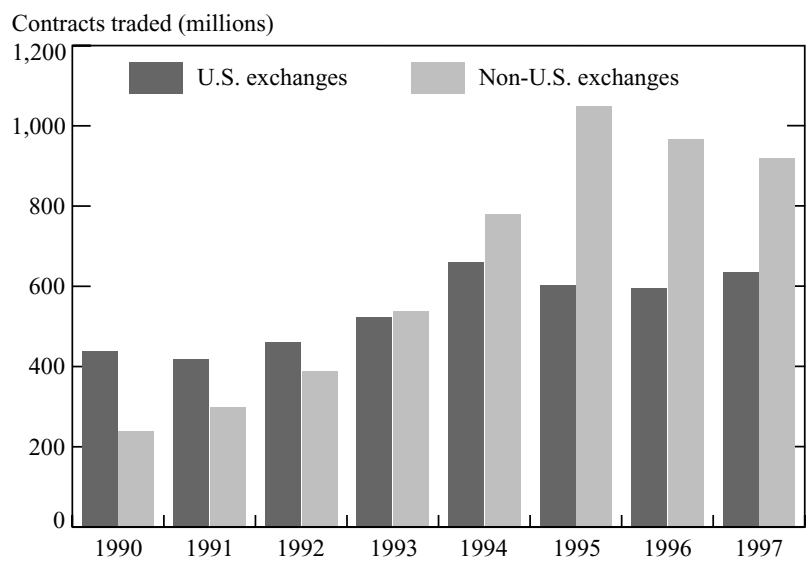

Source: Futures Industry Association.

Notes: The chart shows the volume of futures, options on futures, and options on stock indexes, interest rates, and currencies traded on the world's futures, options, and securities exchanges. Futures and options volume on individual equity securities is not included in the chart. that determine an order's priority. Priority rules on most systems include price and time of entry. In some cases, priority rules may also include order size, type of order, and the identity of the customer who placed the order. In the simplest case, matching occurs when a trader places a buy order at a price equal to or higher than the price of an existing sell order for the same contract. The host computer automatically executes the order, so that trades are matched immediately. Trades are then cleared as they occur, as long as the host computer is linked to the clearinghouse.

With advances in technology, electronic trading has gained momentum. The number of exchanges worldwide that use electronic systems in varying degrees to trade futures and options increased from eight in 1990 to about forty in 1997 (Baptiste, Kang, and Rosenfeld 1993; authors' calculations). Most of these exchanges are located outside the United States. The German Bund futures contract ${ }^{4}$ trades on both an automated exchange in Germany (DTB) and an open outcry exchange in London (LIFFE). DTB's share of the Bund futures volume traded on DTB and LIFFE has increased from 19 percent in 1991 to about 42 percent in 1997 (Chart 2). ${ }^{5}$ Since 1996, at least five open outcry exchanges have either decided to switch from open outcry to electronic trading or are considering such a move. ${ }^{6}$

Even exchanges using open outcry during regular trading hours rely largely on automated systems for afterhours trading. The CBOT's Project A, the CME's Globex, and LIFFE's Automated Pit Trading (APT) are three examples. In 1997, volume on the CME's Globex and the CBOT's Project A increased 118 and 143 percent, respectively, while total volume on these exchanges grew by 13.4 and 9.1 percent, respectively. Growth in volume on LIFFE's APT system has been steady, averaging about 33 percent per year from 1990 to 1997.

In addition, some contracts on open outcry exchanges-including all options and small futures orders on the CME's E-Mini Standard and Poor's 500 contract - trade around the clock on electronic trading systems. On E-Mini's first day of trading in 1997, volume reached nearly 8,000 contracts - the highest opening day volume of any product currently listed on the CME.

\section{Comparing Open Outcry and Electronic Trading}

How effective is the electronic trading system relative to the open outcry method for trading futures and options? The two most important measures of a trading system's effectiveness are its ability to create liquidity and its ability to reduce direct costs for market participants. ${ }^{7}$ Other considerations are availability of information, operating efficiency, and potential for trading abuses (see table). A comparison of the two systems shows that although open outcry trading remains a more 
Chart 2

\section{Share of Bund Futures Volume Traded on DTB and LIFFE}

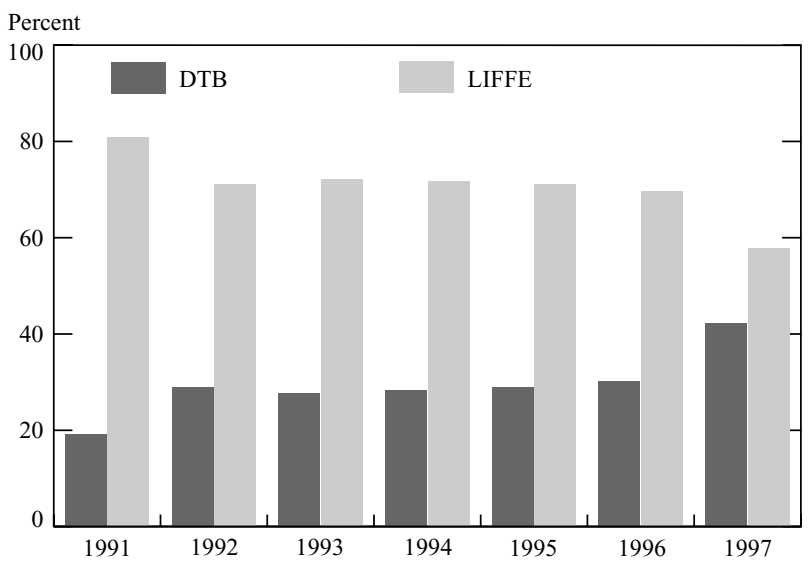

Sources: Futures Industry Association; DTB; LIFFE.

Notes: Bund futures traded on LIFFE's Automated Pit Trading system are subtracted from LIFFE's total Bund futures volume. Bund futures began trading on DTB in November 1990 and on LIFFE in September 1988. Volume is number of contracts traded.

effective method for trading highly active contracts, electronic trading has the potential to enhance the efficiency and cost effectiveness of trading some types of futures and options.

\section{Market Liquidity}

Investors in futures markets need to buy or sell futures contracts quickly and at a fair price. Their ability to do so depends on the existence of traders willing to take the other side of the trade and, in the process, supply liquidity. In a floor trading system, liquidity is supplied by traders who must be continually available for business even when trading activity on the floor is limited. Traders who supply liquidity in an electronic trading system, by contrast, can easily shift their efforts to trade a different contract on the computer screen when trading activity is slow in one contract. Thus, new exchanges, where initial activity in the contracts tends to be low, typically prefer electronic trading systems.

By contrast, the evidence suggests that highly active contracts are better traded on open outcry exchanges than on electronic exchanges. For example, firms that trade large blocks of contracts on DTB complain that they have to pay more than those trading a relatively small number of contracts (Kharouf 1998). Floor traders are skilled at executing large trades and other complex trades such as "stop loss" orders and "spread" trades, with minimal impact on prices. ${ }^{8}$ In particular, locals (floor traders who buy and sell for their own accounts) trade frequently and are important suppliers of liquidity.

Electronic trading systems are not likely to replace the ability of floor traders to execute large and complex trades anytime soon. Although DTB has been successful in wresting market share from LIFFE in the Bund futures contracts, LIFFE still dominates the market for the more complex Bund options contracts. Because the success of locals' trading is largely dependent on observing other traders on the floor, locals tend to avoid screen-based systems. Moreover, complex trades are difficult to enter electronically and may require additional handling. To execute a stop loss order, for example, futures brokers may instruct their clerks to monitor prices manually and then to enter the orders in the electronic system as appropriate.

Nonetheless, improvements in electronic trading systems are increasing the systems' ability to handle large, complex trades. DTB has upgraded its electronic trading system to allow spread trades and to handle more trading activity. In addition, electronic trading systems potentially permit trades that are not possible on open outcry, such as the simultaneous trading of both an asset and a futures contract based on that asset.

Perhaps the greatest advantage of electronic trading is its ability to promote cross-border trading. The experience of DTB, a pioneer in promoting trading by nonresident investors through local access points or direct computer connections, illustrates the potential of remote trading to expand an exchange's business. By November 1997, 65 of DTB's 171 members were remote traders. Electronic exchanges can also form linkages with each other. Domowitz (1995) calls such linkages "implicit mergers" because they increase the capacity of exchanges to handle larger trading volumes at lower cost while providing investors with a wider array of products to trade.

\section{Cost Issues}

On both electronic and open outcry exchanges, member firms bear the fixed costs of operations, which are paid regardless of the volume traded. Fixed costs, determined by the number of traders employed and their salaries, are higher for open outcry markets. Generally, screen-based trading requires less labor, skill, and time. According to DTB calculations, the labor costs of trading the Bund contract on LIFFE are two to three times higher than on DTB (Price Waterhouse 1997). The variable costs of processing customer orders are also lower for electronic trading. However, the initial capital cost to a trader of purchasing a computer workstation is larger than the cost of setting up a floor booth.

Differences in overhead costs are also significant. Exchange overhead costs, which include building, staffing, and back-office costs, tend to be higher for open outcry markets. The CBOT and the New York Mercantile Exchange, for example, recently built new trading pits for $\$ 180$ million and \$228 million, respectively. Electronic exchanges, in contrast, often buy entire trading systems from other exchanges or private companies. With the 
reduction in prices of computer hardware, the cost of buying these systems has fallen dramatically (Domowitz 1995). During 1997, the Swedish electronic exchange OM earned nearly $\$ 40$ million by selling its popular CLICK trading system to several new and existing exchanges.

Higher overhead costs lead to higher fees for members and, ultimately, higher transactions costs for all market participants. Although fees are relatively high in all exchange markets, participants in open outcry markets claim that their fees are particularly high (Lucchetti 1997). LIFFE, for example, charges about $\$ 1.50$ per round turn (that is, for buying and selling a contract) for the Bund futures contract; DTB charges only $\$ 0.66$ per round turn for the same contract. On open outcry exchanges in the United States, exchange fees are about $\$ 1.50$ per round turn (Cavaletti 1997a).

Open outcry exchanges have taken limited steps to reduce costs. In particular, London exchanges have reduced costs by merging their clearing operations. Exchanges in the United States have also recognized the need to cut costs and increase operational efficiency through automation (Massimb and Phelps 1994). Currently, a significant percentage of the CME's and CBOT's annual expenses go to data processing, systems development, and communications - about 25 percent in 1993 alone, for a total of about $\$ 55$ million (Risk Management Center of Chicago 1996). Progress in reducing costs, however, has been slow. Although the Chicago exchanges have spent at least \$20 million to develop hand-held terminals that floor traders can use to record orders and report trades (Miller 1997), the terminals are still in limited use, and the technology is not yet completely reliable. Only about 10 percent of the members of the CME and the CBOT use electronic order routing (Cavaletti 1997b). In addition, except for the

\section{Comparing Open Outcry and Electronic Trading}

\begin{tabular}{lll}
\hline $\begin{array}{l}\text { Main suppliers } \\
\text { of liquidity }\end{array}$ & Locals & Electronic Trading \\
\hline Primary costs & $\begin{array}{l}\text { Upkeep and staffing } \\
\text { of trading floor; } \\
\text { back-office tasks }\end{array}$ & $\begin{array}{l}\text { Large institutions; } \\
\text { market-making firms }\end{array}$ \\
$\begin{array}{lll}\text { Upgrading of software } \\
\text { and hardware; telecom- } \\
\text { munications costs }\end{array}$ \\
$\begin{array}{l}\text { Information } \\
\text { sources }\end{array}$ & $\begin{array}{l}\text { Traders' observations } \\
\text { of market activity }\end{array}$ & $\begin{array}{l}\text { Order book; outside } \\
\text { news sources }\end{array}$ \\
$\begin{array}{l}\text { Operating } \\
\text { efficiency }\end{array}$ & $\begin{array}{l}\text { Large time and labor } \\
\text { investment; potential } \\
\text { for errors }\end{array}$ & $\begin{array}{l}\text { Speed, accuracy, and } \\
\text { transparency }\end{array}$ \\
$\begin{array}{lll}\text { Possible sources } \\
\text { of trading abuse }\end{array}$ & $\begin{array}{l}\text { Lack of precise trade } \\
\text { records; lack of } \\
\text { anonymity in trading }\end{array}$ & $\begin{array}{l}\text { Manipulation of orders } \\
\text { prior to entry }\end{array}$ \\
\hline
\end{tabular}

CME's E-Mini futures contract, the Chicago exchanges have not automated trade execution for small orders during regular trading hours, a step that would likely attract more retail customers. Efforts to merge clearing operations of the Chicago exchanges have not yet succeeded. ${ }^{9}$

\section{Other Points of Comparison}

Both open outcry markets and automated trading systems provide a wealth of information to participants. One of the principal benefits of open outcry, however, is that traders can observe the behavior of other traders on the floor. For example, by noting whether other traders have large buy or sell positions, a trader can infer the future trading behavior of competitors. In addition, because traders' quotes are only valid for an instant, traders can easily revise their quotes in response to unfavorable price movements.

By contrast, traders using electronic trading systems cannot identify counterparties. Further, because traders must actively withdraw quotes from the screen, quote revision takes more time than in open outcry trading. These disadvantages are offset by the fact that electronic traders have real-time access to market analytics and breaking news, information that is not easily accessible from the trading floor. In addition, many electronic trading systems display the "order book" (a list of the current best bids and offers), so that traders can calculate quantities offered and demanded at current prices.

Also notable is the ability of electronic trading to virtually eliminate errors in recording orders and reporting trades, resulting in significant cost savings. Customer orders in open outcry markets go through several intermediaries before reaching the trading floor, increasing processing time and the chance of errors in recording orders. "Out trades," or error trades, occur when floor traders mistakenly report the same trade differently. With electronic trading systems, out trades cannot occur, and mistakes in recording orders only slip through when orders are typed into the computer incorrectly.

Neither open outcry nor electronic exchanges can completely eliminate illegal trading activity. On the trading floor, traders may behave opportunistically by colluding with other traders to prearrange customer trades, by taking the opposite side of a customer order without exposing it to the market (noncompetitive trading), or by trading ahead of the order (front running). In electronic trading, brokers may withhold customer orders prior to execution. In addition, the ability to move easily among contracts on the screen may lead to the manipulation of customer orders. ${ }^{10}$

Electronic trading systems on the whole, however, are easier to regulate than open outcry trading. Clearing firms 
can monitor the risk position of traders as trades occur. Because trades are recorded accurately and in detail, regulators can monitor all transactions and spot suspicious patterns in the data.

Interestingly, existing research regarding the relative merits of open outcry and electronic trading does not clearly favor either method. Empirical studies comparing the cost of trading in electronic and open outcry markets have mostly focused on the German Bund futures contract. Unfortunately, results from these studies often contradict each other and are undermined by data limitations. ${ }^{11}$ Still, the potential for electronic trading to improve efficiency and to reduce costs for both exchanges and traders seems difficult to ignore.

\section{What's Ahead}

In Khan and Ireland's (1993) survey of futures and options market participants, traders opposed to electronic trading spoke of the "smell" and "buzz" of open outcry trading, and the importance of these intangible factors in trading decisions. A new generation of traders, at ease with computers, may feel more friendly toward electronic trading. Price Waterhouse (1997) reports increased support for electronic trading systems among brokers and fund managers. The new generation of computer-friendly traders, who may include large institutional traders and market-making firms, will likely supplant locals as liquidity suppliers to electronic trading systems. For example, the recent surge in volume of DTB's Bund futures contracts has come mostly from new members.

The prospects for electronic trading may be further advanced by the European Monetary Union scheduled to begin in 1999. To promote cross-border trading, electronic exchanges can provide remote access for nonresident investors and form cooperative links with independent exchanges. The first electronic link between independent exchanges took place in early 1997. Exchanges in London, Oslo, and Stockholm allowed 130 members from seven countries to trade futures and options in real time. More recently, futures exchanges in France, Germany, and Switzerland adopted a common electronic trading and clearing platform.

Open outcry exchanges also extend their markets by establishing links with exchanges in different time zones, but in a more limited way than electronic exchanges. Both the number of participants and the range of contracts in open outcry markets are constrained by the size of the trading floor. For example, in 1997, an open outcry trading link between LIFFE and the CBOT suffered from low trading volume and was eventually canceled. Instead, LIFFE has chosen to concentrate on electronic trading systems for its after-hours links with other exchanges. The CBOT is in the process of installing several Project A electronic trading terminals in Europe and the Far East.

Despite the potential benefits of automating trading operations, open outcry exchanges have often faced opposition to such efforts from some trader members. For early adopters of electronic trading systems, the costs (such as learning new skills and incompatibility with floor trading) may appear to outweigh the benefits. Because of this hurdle, the benefits realized by automating trading operations must be substantial before exchange members will support electronic trading (Domowitz 1995). To overcome resistance, some open outcry exchanges are sharing the benefits of automation with members. The CBOT, for example, shares 70 percent of profits from Project A with full exchange members and 20 percent with clearing members.

\section{Conclusion}

Electronic trading systems have become increasingly popular in the past decade and currently account for about one-fifth of volume on futures exchanges. Driving this rise in popularity is the potential for electronic trading to improve efficiency and lower costs. In addition, electronic trading systems make exchanges available to remote investors in real time, an important benefit in a period of increased cross-border trading.

On open outcry exchanges, skilled floor traders continue to provide high levels of liquidity for outside customers. However, even these exchanges have adopted electronic trading systems for selected products and for after-hours trading. As technology advances, the trading process on futures exchanges is likely to become increasingly automated and the volume of electronically traded futures and options contracts should grow rapidly.

\footnotetext{
Notes

1. A futures contract is an agreement between two parties to buy or sell an asset at a set price on a particular date. An options contract gives the option purchaser the right, but not the obligation, to buy or sell an asset at a specified price on or before a specified date.

2. Figures for exchange-traded products include futures, options on futures, and options on stock indexes, interest rates, and currencies. U.S. futures exchanges trade only futures and options on futures. Other types of options, such as options on stock indexes or individual stocks, are traded on U.S. securities exchanges, which are not the subject of our study.

3. Sundel and Blake (1991) and Domowitz (1992) compare alternative electronic systems.

4. The German Bund futures contract is based on long-term notional debt securities issued by the German federal government, or the Treuhandanstalt, with a term of 8.5 to 10.5 years and an interest rate of 6 percent.
} 
5. Exchange data were supplied by the various exchanges and the Futures Industry Association.

6. For example, the Sydney Futures Exchange of Australia, one of the twenty largest futures exchanges in the world, recently decided to adopt electronic trading.

7. See Khan and Ireland (1993) for a comparison of the two systems that is based on a survey of market participants and exchange managers in Europe.

8. With stop loss orders, traders buy or sell the contract when it reaches a specified price. Spread trades involve the simultaneous purchase and sale of two different futures contracts.

9. A promising development is Clearing 21, a joint venture of the CME and the New York Mercantile Exchange that allows real-time trade processing.

10. See Sundel and Blake (1991) for a discussion of trading abuses on electronic trading systems.

11. Of studies comparing trading costs between DTB and LIFFE, Pirrong (1996) concludes that volatility was lower and liquidity higher on DTB, but Shyy and Lee (1995) come to the opposite conclusion. Kofman and Moser (1997) find no difference in liquidity but suggest that there may be more information-based trading on DTB. Breedon and Holland (1997) argue that the results obtained are highly sensitive to whether quote data or transactions data are used.

\section{References}

Baptiste, Antonio, Jane C. Kang, and Robert H. Rosenfeld. 1993. "Survey Shows Electronic Systems Multiplying." Futures Industry 3, no. 1 (January-February): 11-6.

Breedon, Francis, and Allison Holland. 1997. "Electronic versus Open Outcry Markets: The Case of the Bund Futures Contract." Bank of England Working Paper no. 76, August.

Cavaletti, Carla. 1997a. "Commission Rate Ride." Futures 26, no. 12 (October): 68-70.

1997b. "Electronic Order Routing: Quick, Efficient, and Controversial." Futures 26, no. 2 (February): 68-70.
Domowitz, Ian. 1992. "Automating the Price Discovery Process: Some International Comparisons and Regulatory Implications." Journal of Financial Services Research 6, no. 4: 305-26.

1995. "Electronic Derivative Exchanges: Implicit Mergers, Network Externalities, and Standardization." Quarterly Review of Economics and Finance 35, no. 2: 163-75.

Khan, B., and J. Ireland. 1993. "The Use of Technology for Competitive Advantage: A Study of Screen versus Floor Trading." City Research Project, Subject Report 4. Corporation of London.

Kharouf, Jim. 1998. "German Engineering Goes a Long Way." Futures 27, no. 1 (January): 78-81.

Kofman, P., and J. T. Moser. 1997. "Spreads, Information Flows, and Transparency across Trading Systems." Journal of Applied Financial Economics 7, no. 3: 281-94.

Lucchetti, Aaron. 1997. "Futures Firms Weigh Starting New Trade Plan.” Wall Street Journal, August 29, C1.

Massimb, Marcel N., and Bruce D. Phelps. 1994. "Electronic Trading, Market Structure, and Liquidity." Financial Analysts Journal 50, no. 1: 39-50.

Miller, Merton H. 1997. "The Future of Futures." Pacific-Basin Finance Journal 5, no. 2: 131-42.

Pirrong, Craig. 1996. "Market Liquidity and Depth on Computerized and Open Outcry Trading Systems: A Comparison of DTB and LIFFE Bund Contracts." Journal of Futures Markets 16, no. 5: 519-43.

Price Waterhouse. 1997. The Impact of Technology on the Futures and Options Industry. Futures and Options Association, London.

Risk Management Center of Chicago. 1996. Chicago's Exchange Community, November.

Shyy, G., and J. H. Lee. 1995. "Price Transmission and Information Asymmetry in Bund Futures Markets: LIFFE versus DTB." Journal of Futures Markets 15, no. 1: 87-99.

Sundel, Michael B., and Lystra G. Blake. 1991. "Good Concept, Bad Executions: The Regulation and Self-Regulation of Automated Trading Systems in United States Futures Markets." Northwestern University Law Review 85, no. 3: 748-89.

\section{About the Authors}

Asani Sarkar is an economist and Michelle Tozzi an assistant financial/economic analyst in the Capital Markets Function of the Research and Market Analysis Group.

The views expressed in this article are those of the authors and do not necessarily reflect the position of the Federal Reserve Bank of New York or the Federal Reserve System.

Current Issues in Economics and Finance is published by the Research and Market Analysis Group of the Federal Reserve Bank of New York. Dorothy Meadow Sobol is the editor.

Subscriptions to Current Issues are free. Write to the Public Information Department, Federal Reserve Bank of New York, 33 Liberty Street, New York, N.Y. 10045-0001, or call 212-720-6134. Back issues are also available. 